Chronic Obstructive Pulmonary Diseases:

Journal of the COPD Foundation

\author{
Original Research
}

\title{
Internet Health Behaviors of Patients with Chronic Obstructive Pulmonary Disease and Assessment of Two Disease Websites
}

Donald A. Mahler, MD, FCCP ${ }^{1,2}$ Frank Cerasoli, $\mathrm{PhD}^{3}$ Lindsay Della, $\mathrm{PhD}^{4}$ Mark Rudzinski, MBA ${ }^{5}$

\begin{abstract}
Background: Little is known about patients' use of the internet to search for information about chronic obstructive pulmonary disease (COPD) and their perspectives on disease content on websites.

Objectives: To determine the interests and behavior of patients with COPD who search the internet for disease information and to assess their perspectives about 2 COPD educational websites.

Methods: Individuals with COPD who had registered for a consumer panel were invited electronically to participate in a survey which included general use of the internet, online health behaviors about COPD, and assessment of 2 COPD educational websites.

Results: A total of 445 respondents completed the survey in $23 \pm 12$ minutes ( $72 \%$ response rate). A total of 95\% reported that physicians were the primary source of information about COPD followed by internet searches about the disease (76\%). The 3 major information priorities were "symptom control" (82\%), "how COPD is affecting my body" (60\%), and "treatments that might work better for me" (59\%). Overall ratings (range, $1-10)$ were $7.4 \pm 1.5$ for the American Lung Association and 6.8 \pm 1.8 for the COPD Foundation websites. Ratings by respondents were higher for all 5 impression attributes and for 8 of 9 content attributes on the American Lung Association website compared with the COPD Foundation website.

Conclusions: This report describes, for the first time, information priorities of patients with COPD about their disease and their assessment of 2 educational websites. Our survey results can be used by health care professionals to recommend online resources to their patients.
\end{abstract}

Abbreviations: chronic obstructive pulmonary disease, COPD; American Lung Association, ALA; modified Medical Research Council, mMRC; 6-minute walk test, 6MWT; standard deviation, SD; nurse practitioner, NP; physician's assistant, PA; respiratory therapist, RT; pharmaceutical, Rx; electronic medical record, EMR; health care provider, HCP; degrees of freedom, $\mathrm{df}$

Funding Support: This study was supported by a grant from Sunovion Pharmaceuticals LLC to the CHEST Foundation.

Date of Acceptance: January 8, 2018

Citation: Mahler DA, Cerasoli F, Della L, Rudzinski M. Internet health behaviors of patients with chronic obstructive pulmonary disease and assessment of two disease websites. Chronic Obstr Pulm Dis. 2018;5(3):158-166. doi: https://doi.org/10.15326/jcopdf.5.3.2017.0173

1 Emeritus Professor of Medicine, Geisel School of Medicine at Dartmouth, Hanover, New Hampshire

2 Valley Regional Hospital, Claremont, New Hampshire

3 Medical Dynamics, New York, New York

4 University of Louisville, Louisville, Kentucky

5 Rockpile Strategies LLC, LaGrange, Illinois

\section{Address correspondence to:}

Donald A. Mahler, MD

Valley Regional Hospital

243 Elm Street

Claremont, NH 03743

Phone: 603 277-0383

Email: mahlerdonald@gmail.com

\section{Keywords:}

internet; chronic obstructive pulmonary disease; COPD; COPD websites; breathlessness; exacerbations 


\section{This article has an online data supplement.}

\section{Introduction}

The internet is an increasingly important source of health information for the public. However, little information is known about patients' perspectives on disease-specific online education materials. ${ }^{1-4}$ This is an important consideration if the goal of a website is to provide high quality and practical health information. Knowledge about a medical condition has the potential to empower patients to participate in collaborative selfmanagement to improve health outcomes. ${ }^{5}$ Health care professionals should be aware of both disease content on the internet as well as patients' perspectives of this information in order to recommend specific websites to complement health care discussions.

Two previous reports have characterized the use of internet-based educational materials by patients with chronic obstructive pulmonary disease (COPD). ${ }^{6,7}$ In 2014, Martinez and colleagues ${ }^{6}$ described internet access and use in a 2007-08 convenience sample of 12,694 patients with COPD. The survey was completed by 914 individuals (7.2\% completion). ${ }^{6}$ More frequent use of the internet (at least weekly) was associated with younger age, while some respondents expressed dissatisfaction with care based on insufficient time with the physician. ${ }^{6}$ In 2015 , Delgado and colleagues ${ }^{7}$ described use of the internet to obtain health information among 382 patients with COPD living in Brazil. The 17-item paper survey was distributed among different socioeconomic levels of the Brazilian population. Internet use was statistically associated with having a computer, a low level of dyspnea, and high socioeconomic status. ${ }^{7}$ These surveys are important, but incomplete, in understanding why patients seek online information and what topics are of interest.

The purpose of this research was to gain insight into how patients with COPD perceive web-based health information. The 3 objectives were to: (1)determine behaviors of patients with COPD in use of the internet to learn about their disease; (2)assess the perspectives of patients with COPD about disease content on 2 educational websites - those sponsored by the American Lung Association (ALA) and the COPD Foundation; and (3)determine whether patient characteristics, such as older age, severity of breathlessness on the modified Medical Research Council (mMRC), ${ }^{8}$ and number of exacerbations in the past year affected internet health behaviors and assessment of COPD educational websites. Both symptoms and exacerbation history are discriminative variables recommended for assessment of patients with COPD in the 2017 report of the Global Initiative for Chronic Obstructive Lung Disease. ${ }^{9}$

\section{Methods}

This study is an investigator-initiated proposal to the CHEST Foundation to perform a survey of patients with COPD about their use of the internet to obtain diseasespecific health information. The CHEST Foundation obtained funding from Sunovion Pharmaceuticals LLC and contracted with Rockpile Strategies LLC for survey development, implementation, and analyses. The online survey was conducted in accordance with the amended Declaration of Helsinki and was exempt from Institutional Review Board approval according to category 2 of 45 CFR 46.101(b) of the American Association of Public Opinion Research.10 By completing the survey, respondents gave consent to allow their responses to be used for research purposes. The investigators had complete autonomy for all aspects of the study including decision on submission.

\section{Survey}

All items of the survey were developed by the authors who have expertise in market research and COPD. After one of the authors (MR) created the initial draft of the survey, it was sent electronically to 2 coinvestigators (DAM and FC) for review. Then, a conference call was convened for review and discussion of each item. Based on the discussion, additional items were added such as participant ratings of breathlessness on the mMRC scale $^{8}$ and number of exacerbations experienced in the past year as recommended for categorizing patients with COPD. ${ }^{9}$ Additional changes were also made, and the survey was again reviewed independently by the 3 investigators. A second conference call was held for further review of each item with minor final changes made. The complete survey is provided in the online supplement. Using the Flesch-Kinkaid Grade Level readability test, the survey was scored as 8.4, which translates into an 8th grade reading level.

Part 1 (33 items) included screening criteria, patient demographics, ratings of breathlessness on the mMRC scale $^{8}$ and number of exacerbations experienced in the past year, general use of the internet, online 
health behaviors, and the types of information sought about COPD. Part 2 included 3 screenshots for each of 2 websites. This approach was used to provide standardized information for assessment by respondents. After viewing the screenshots for each website, respondents answered 19 items and provided an overall rating of that website as well as general comments ( 2 items). The entire survey was designed to be completed within 25 minutes. Data were collected from December 2 - 18, 2016.

\section{Respondents}

Individuals who had registered for the consumer panel of Research Now, an online market research company, were contacted electronically to invite participation. ${ }^{11}$ Inclusion criteria were: 50 - 80 years of age; living in the United States; a COPD diagnosis by a health care provider; and previous use of a computer to search the internet for health information. An exclusion criterion was currently working for a health care entity. Those who completed the survey received "e-rewards" used to purchase e-gift cards from business partners. ${ }^{11}$ The estimated value for completion of this survey was $\$ 2.00$.

\section{Website Selection}

After review of major COPD educational websites, ${ }^{1}$ the authors selected those sponsored by the ALA (www.lung.org) ${ }^{12}$ and the COPD Foundation (www. copdfoundation.org) ${ }^{13}$ for assessment. These websites were selected as being sponsored by prominent organizations that include specific educational materials directed to individuals with COPD that could be compared by respondents.

The mission of the ALA is "to save lives by improving lung health and preventing lung disease."12 Information about COPD is listed as one of 6 topics under the heading "Lung Health and Disease" on the website. Additional clicks are required to view specific aspects of COPD (e.g., learn about COPD; symptoms, causes, and risk factors; diagnosing and treating COPD; and living with COPD).

The COPD Foundation was established "to undertake initiatives that result in expanded services for COPD and to improve the lives of individuals affected by COPD." 13 Education, advocacy, and research are major objectives of the organization. The website has headings for patients, caregivers, family and friends, and medical professionals to learn about COPD. The website features an interactive online community called "COPD360Social" that allows viewers to learn about events in their area, participate in research, and chat with experts. ${ }^{13}$

Details of website presentation and evaluation are provided in Table 1. The order of presentation of the 2 websites was alternated to eliminate order bias. After rating each website, respondents were able to provide open-ended comments about each website.

\section{Statistical Analysis}

Results of competed surveys are presented based on recommendations for reporting web-based surveys.14 Demographic data are presented as mean \pm standard deviation (SD). Comparisons were performed based on participants' age ( $<65$ versus $\geq 65$ years) as well as $\mathrm{mMRC}$ scale score ( $0-1$ versus $\geq 2$ ) and number of exacerbations of COPD by self-report in the past year ( $0-1$ versus $>2$ ) as outcomes recommended by the Global Initiative for Obstructive Lung Disease. ${ }^{9}$ Data were analyzed using StatPac Software version 16 (Bloomington, Minnesota). Depending on the type of data, a 2-tailed independent t-test or a chi-square test were used. To compare respondents' ratings of the 2 websites, paired t-tests were performed after adjusting for multiple comparisons using a Bonferroni adjustment.

\section{Results}

Of the 1070 respondents who began the survey, 33 were disqualified because they did not meet the age criterion, and 418 were excluded because they had not searched the internet for health information. Of the remainder, 445 respondents answered all items on the survey, resulting in a completion rate of $72 \%$. The 263 females (59\%) and 182 males (41\%) were $65 \pm 7$ years of age and completed the survey in $23 \pm 13 \mathrm{~min}$.

Respondent demographics are described in Table 2. Labored breathing when performing physical activities was the most frequently reported symptom (72\%). The majority of respondents had an mMRC score of 0-1 (59\%) and had experienced 0-1 exacerbation in the past year (54\%).

\section{Internet Use}

Figure 1 shows the frequency of respondents using the internet to search for general health information. 


\title{
Table 1. Website Presentation and Evaluation
}

\begin{abstract}
Presentation
1. All references to the organization identity and any branding were digitally removed from the screenshots.

2. For each site, the first screenshot viewed by the respondent was the site's main landing page (Online Supplement, Figures 1 and 2). This was followed by 2 additional screenshots from site containing content on COPD that represented a unique approach to patient education. Each screenshot was held in place for 15 seconds to ensure that the respondent did not "speed" through screenshots in an effort to complete the survey as quickly as possible. Respondents could not navigate the sites during the course of the survey, but could clearly see the structure and information links on each site. This approach provided standardized information for each respondent to assess.
\end{abstract}
Evaluation of Each Website
1. Respondents answered 19 questions regarding attributes and overall reaction after viewing the 3 screenshots for the first site. The same set of tasks was repeated for the remaining website. Respondents selected a score from 1 to 5 (range, 1 "strongly disagree" to 5 "strongly agree") for impression and content attributes.
2. After viewing each website, respondents selected a score (range, 1 "poor" to 10 "excellent") for overall reaction.
3. Respondents provided open comments about why they preferred each website.

Internet use "several times a day" was significantly greater in participants $<65$ years of age ( $59 \%$ versus $50 \%$; $=1.98, p<0.05)$.

\section{COPD Health Information Behaviors and Priorities}

Figure 2 shows the type of information about COPD sought by respondents on the internet. A greater percentage of those with more frequent exacerbations sought specific information about COPD (64\% versus $48 \% ; z=3.38, p<0.05)$ and reviews of different treatments ( $53 \%$ versus $41 \%$; $z=2.52, p<0.05$ ). The top 3 information priorities sought by respondents were "symptom control" ( $82 \%)$, "how COPD is affecting my body" (60\%), and "treatments that might work better for me" (59\%). A greater percentage of those with $\geq 2$ exacerbations in the past year were interested in COPD symptom control (88\% versus $77 \%$; $\mathrm{z}=3.01, p<0.05$ ), different treatment options ( $66 \%$ versus $53 \%$; $z=2.77$, $p<0.05$ ), and reducing the frequency of exacerbations ( $67 \%$ versus $29 \% ; z=7.99, p<0.05$ ) compared with those who reported $0-1$ exacerbation in the past year. Respondents with $\mathrm{mMRC} \geq 2$ reported a high interest in information on treatment options ( $67 \%$ versus $54 \%$; $z=2.75, p<0.05)$ and reducing exacerbations $(60 \%$ versus $37 \% ; z=4.79, p<0.05)$ compared with those who had less breathlessness.

\section{Sources of Information about COPD}

Sources of information about COPD used by the respondents are shown in Figure 3. When combining responses "sometimes" and "frequently," 95\% of respondents reported that physicians were their primary source of information about COPD followed by searches of the internet (76\%). Almost one-third (32\%) indicated that they brought information from the internet with them to an office visit "sometimes" or "most/all of the time" for discussion (Table 3 ).

\section{Assessment of COPD Websites}

Respondents' ratings of overall reaction to the websites were: $7.4 \pm 1.5$ for the ALA and $6.8 \pm 1.8$ for the COPD Foundation. Ratings were higher for information on the ALA website compared with the COPD Foundation website for the 5 impression attributes and for 8 of 9 content attributes (Table 4 and online supplement figures 1 and 2). Age, mMRC score, and exacerbation frequency did not differentiate respondents' overall ratings of the 2 websites ( $p>0.05$ for all comparisons).

Respondents provided the following most frequent reasons for their ratings of each website: for the ALA - good general review (41\%), generic information (21\%), and organized and easy to navigate (17\%); for the COPD Foundation - lots of information covering COPD (31\%), too general for newly diagnosed patients (16\%), and liked the question and answer format with other patients (13\%).

\section{Discussion}

The major findings of this online survey completed 


\section{Table 2. Demographic Information of the $\mathbf{4 4 5}$ Respondents}

\section{Number of respondents (Percentage)}

Age (years)

$65 \pm 7$ (mean \pm standard deviation)

\begin{tabular}{lr}
\hline$<65$ & $200(45 \%)$ \\
\hline$\geq 65$ & $245(55 \%)$ \\
\hline Education & $182(41 \%)$ \\
\hline College Graduate & $165(37 \%)$ \\
\hline Attended College & $98(22 \%)$ \\
\hline High School Graduate or Less & \\
\hline Residence - Region of Country & \\
\hline Midwest & $89(20 \%)$ \\
\hline Northeast & $89(20 \%)$ \\
\hline South & $160(36 \%)$ \\
\hline West & $107(24 \%)$ \\
\hline Self-reported Health Status & $5(1 \%)$ \\
\hline Excellent & $62(14 \%)$ \\
\hline Very good & $160(36 \%)$ \\
\hline Average & $169(38 \%)$ \\
\hline Fair & $49(11 \%)$ \\
\hline Poor & \\
\hline Level of Concern About Health & $5(1 \%)$ \\
\hline Not at all concerned & $58(13 \%)$ \\
\hline Not too concerned & $227(51 \%)$ \\
\hline Somewhat concerned & $155(35 \%)$ \\
\hline Very concerned &
\end{tabular}

Most Frequently Reported Symptoms

(Participants could select multiple options)

\begin{tabular}{ll}
\hline Labored Breathing & $320(72 \%)$ \\
\hline Wheezing & $258(58 \%)$ \\
\hline Cold More Frequently & $151(34 \%)$ \\
\hline Difficulty Sleeping & $120(27 \%)$ \\
\hline
\end{tabular}

\section{modified Medical Research Council Scale Score}

\begin{tabular}{ll}
\hline $0-1$ & $263(59 \%)$ \\
\hline$\geq 2$ & $182(41 \%)$ \\
\hline
\end{tabular}

Number of Self-reported Exacerbations in Past 1 Year

\begin{tabular}{lr}
\hline $0-1$ & $240(54 \%)$ \\
\hline$\geq 2$ & $205(46 \%)$ \\
\hline $\begin{array}{l}{ }^{a} \text { According to the National Geographic Society. For purposes of } \\
\text { this survey, Southeast and Southwest regions are combined } \\
\text { into the South. }\end{array}$
\end{tabular}
into the South.

by 445 respondents with COPD were: (1)physicians were the primary source of information about the disease followed by internet searches about COPD; (2)COPD health searches focused on 2 areas - specific information about COPD and treatments for the disease; (3)priorities about disease information, in rank order, were "symptom control," "how COPD affects my body," and "treatments that might work for me;" and (4) most attributes were rated higher for the ALA website compared with the COPD Foundation website.

\section{Figure 1. Frequency of Searching the Internet for Health Information}

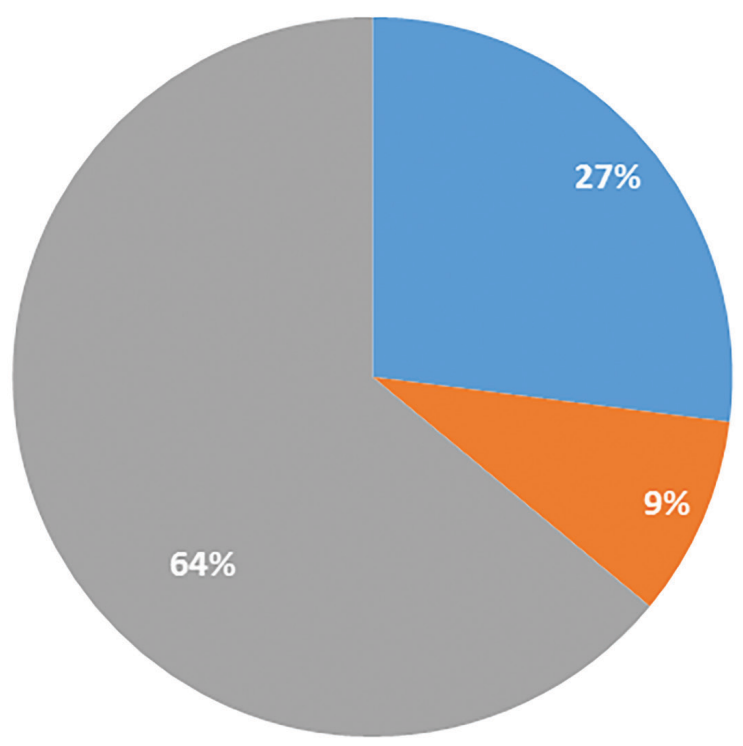

$\square 2-3 x /$ month $\square 1 x /$ week $\square$ Every few months

\section{Figure 2. Types of Information About COPD Sought on the Internet}

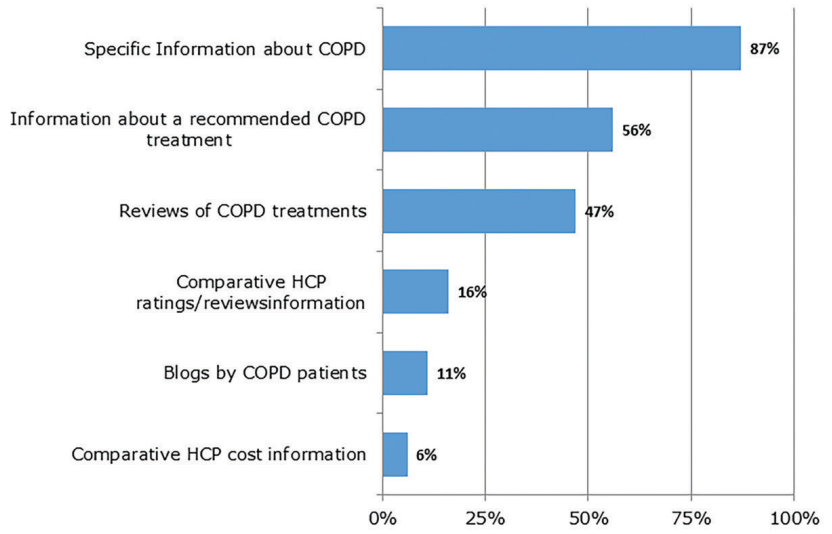

Although the respondents were self-selected, their general characteristics appear representative of the heterogeneous COPD population based on age, gender (slightly more females), geographical residence (slightly more live in southern United States), most frequently reported symptom ("labored breathing"), severity of shortness of breath, and number of exacerbations in the past year (Table 2). However, our respondents had 2 unique features. All were required to have previously searched the internet for health 


\section{Figure 3. Sources of Information about COPD as Reported by the Participants}

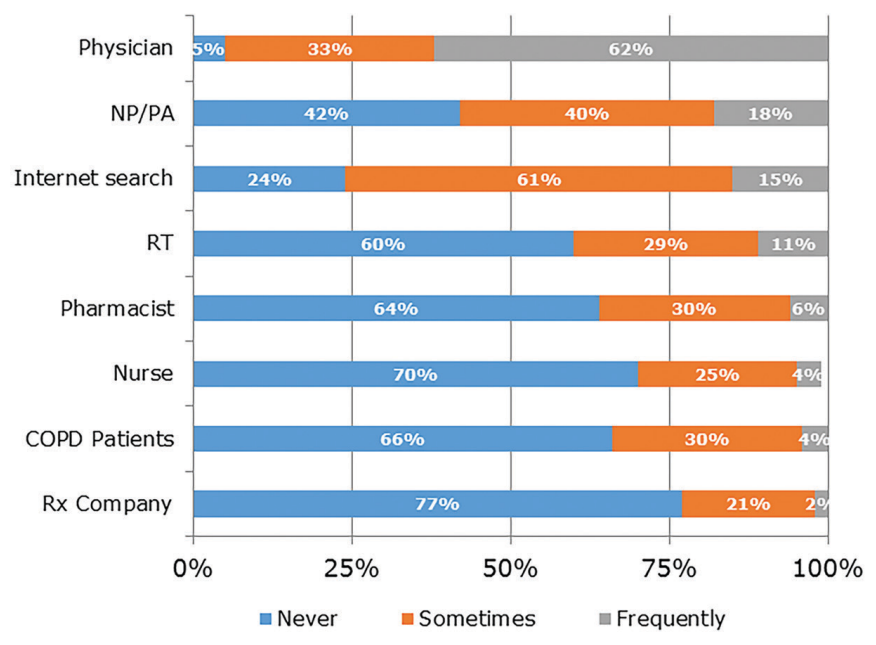

$\mathrm{NP}=$ nurse practitioner; $\mathrm{PA}=$ physician's assistant;

$\mathrm{RT}=$ respiratory therapist; $\mathrm{Rx}=$ pharmaceutical

\section{Table 3. Internet Use for General and COPD Health Information of the $\mathbf{4 4 5}$ Respondents}

Number of respondents (Percentage)

\section{Frequency of General Internet Use ${ }^{a}$}

\begin{tabular}{l|r}
\hline $2-3$ times/week & $27(6 \%)$ \\
\hline Daily & $178(40 \%)$ \\
\hline Several times/day & $240(54 \%)$ \\
\hline
\end{tabular}

\section{Online Health Behaviors}

(Participants could select multiple options)

\begin{tabular}{l|l}
\hline Accessing EMR & $289(65 \%)$ \\
\hline Enrolled in payor portal & $223(50 \%)$ \\
\hline Email to HCP & $196(44 \%)$ \\
\hline Paid a medical bill & $191(43 \%)$ \\
\hline "Liked" a health organization & $136(30 \%)$ \\
\hline
\end{tabular}

\section{Frequency of Searching for Health Information on Internet}

\begin{tabular}{l|r}
\hline $2-3$ times/month & $120(27 \%)$ \\
\hline Once a week & $40(9 \%)$ \\
\hline Every few months & $285(64 \%)$ \\
\hline
\end{tabular}

\section{Bring Online Information for COPD-related Outpatient Visit}

\begin{tabular}{l|r}
\hline Never & $142(32 \%)$ \\
\hline Infrequently & $165(37 \%)$ \\
\hline Sometimes & $116(26 \%)$ \\
\hline Most or all of the time & $22(5 \%)$ \\
\hline
\end{tabular}

aemail, shopping, banking, social media, etc

$\mathrm{EMR}=$ electronic medical record; $\mathrm{HCP}=$ health care provider information in order to complete the online survey. The respondents were generally well educated as 99\% graduated from high school and $41 \%$ graduated from college. We believe that their overall education level was more than adequate to understand and answer survey items written at an 8 th grade reading level.

Ninety-five percent of our respondents reported that they rely heavily on their physician as their primary source of information about COPD. However, as many health care systems have placed greater demands on health care professionals, available time for discussions in the office may be limited. In 2010, the National Ambulatory Medical Survey reported that physicians spent an average of 20.8 minutes for outpatient visits. ${ }^{15}$ Many follow-up office appointments are scheduled for 15 minutes regardless of the complexity and comorbidities of the individual patient. As a result, patients are increasingly using the internet for health inquiries. In 2013, the Pew Research Center found that $72 \%$ of adult internet users in the United States sought online health information within the past year. ${ }^{16}$ Similarly, $76 \%$ of our respondents indicated that they performed internet searches about COPD, which was the second most frequent approach to learning about their disease.

Previous surveys of patients with COPD have queried respondents about their symptoms, quality of life, as well as other aspects of the disease. ${ }^{6,7,17-20}$ Three of these surveys illustrate that gaps exist between perceptions of patients with COPD and physicians about the effects of the disease on daily life. ${ }^{18-20}$ Of note, patients' responses to surveys may offer more accurate information as Celli and colleagues ${ }^{20}$ found that the majority of 334 patients with COPD stated that they were not completely frank with their physicians during visits. Although 2 studies have assessed internet search behaviors among COPD patients, ${ }^{6,7}$ to our knowledge this report is the first to describe priorities about their disease among respondents. One strength of our survey findings is the $72 \%$ completion rate compared with much lower rates (7\%-29\%) observed in other surveys of individuals with COPD. ${ }^{6,20}$

Our study describes, for the first time, patients' assessments of website information about a respiratory disease. Patients rated content of both websites as "good" with mean overall ratings of approximately 7 out of 10 . These scores suggest that there is an opportunity to improve online materials to achieve 


\section{Table 4. Ratings of Different Attributes for Each COPD Website}

\begin{tabular}{|c|c|c|c|c|c|}
\hline Attribute $^{a}$ & ALA & $\begin{array}{c}\text { COPD } \\
\text { Foundation }\end{array}$ & t-value & df & $p$-value \\
\hline \multicolumn{6}{|l|}{ Impression } \\
\hline Information is trustworthy & $4.1 \pm 0.9$ & $3.7 \pm 1.0$ & 9.11 & 442 & 0.0001 \\
\hline Easy to understand & $4.3 \pm 0.8$ & $3.9 \pm 1.0$ & 7.20 & 438 & 0.0001 \\
\hline Visually appealing & $4.0 \pm 1.0$ & $3.6 \pm 1.2$ & 6.33 & 434 & 0.0001 \\
\hline Presented in a direct manner & $4.2 \pm 0.9$ & $3.8 \pm 1.2$ & 7.70 & 435 & 0.0001 \\
\hline Relevant to me & $4.2 \pm 0.9$ & $3.8 \pm 1.2$ & 6.26 & 416 & 0.0001 \\
\hline \multicolumn{6}{|l|}{ Content } \\
\hline Applicable to me & $4.0 \pm 1.0$ & $3.6 \pm 1.2$ & 6.45 & 444 & 0.0001 \\
\hline Information is general & $3.3 \pm 1.2$ & $3.4 \pm 1.1$ & -1.59 & 444 & 0.1125 \\
\hline Information is comprehensive & $4.0 \pm 1.0$ & $3.6 \pm 1.2$ & 6.29 & 444 & 0.0001 \\
\hline Information is up-to-date & $4.0 \pm 0.9$ & $3.7 \pm 1.2$ & 5.49 & 444 & 0.0001 \\
\hline Information comes from a leading authority on COPD & $4.1 \pm 0.9$ & $3.6 \pm 1.2$ & 7.58 & 444 & 0.0001 \\
\hline Provides practical guidance on how to manage COPD & $4.1 \pm 0.9$ & $3.6 \pm 1.2$ & 8.03 & 444 & 0.0001 \\
\hline Website is regularly updated & $3.9 \pm 0.9$ & $3.6 \pm 1.1$ & 5.19 & 444 & 0.0001 \\
\hline Learn new things about COPD that I wouldn't find elsewhere & $3.9 \pm 1.1$ & $3.6 \pm 1.2$ & 3.76 & 444 & 0.0002 \\
\hline I would bookmark this site to go back to it & $3.8 \pm 1.2$ & $3.5 \pm 1.4$ & 5.08 & 444 & 0.0001 \\
\hline
\end{tabular}

aattributes were rated as $1-5$ with $1=$ "strongly disagree" and $5=$ "strongly agree"

$\mathrm{ALA}=$ American Lung Association; $\mathrm{df}=$ degrees of freedom

higher patients' ratings. Assessments of specific features indicate that respondents provided higher ratings for all 5 impression attributes and for 8 of 9 content attributes on the ALA website compared with the COPD Foundation website (Table 4). These differences highlight preferences by respondents for COPD health information and how it is delivered. Interestingly, patients' age, level of breathlessness on the $\mathrm{mMRC}$, and history of exacerbations did not affect patients' ratings of website attributes. Whether other factors such as socioeconomic status, occupation, or severity of disease are associated with patients' preferences requires further investigation.

In evaluating the reasons provided by respondents for their ratings of the websites, we were impressed with the heterogeneity of comments. The following statements summarize comments by respondents to the last 2 items on the survey: (1)the ALA website successfully blended content with visual appeal along with links to other resources; and (2)the COPD Foundation website provided content geared for newly diagnosed patients and offered a supportive community for all COPD patients. While many individuals liked the social platform and opportunity to interact with other patients on the COPD Foundation website, others were less interested in engaging socially and preferred authoritative guidance about the disease. These general responses illustrate that multiple educational approaches are important in order to provide both interesting and informative content about COPD on the internet. Identifying characteristics of respondents who preferred specific types of website content and opportunities to interact is an area of future research.

The study has several limitations. First, our respondents were self-selected which may introduce bias. Certainly, our findings may not be applicable to other patients with COPD as respondents were required to have used a computer to search the internet for health information. Because patients with COPD may not have experience using a computer, printed materials and/or videos will remain important tools to learn about their disease. Second, respondents viewed 3 screenshots of each website which reflects only a sample of available information. However, we attempted to provide representative screens highlighting differentiating features of each website. This approach provided standardized information for viewing and assessment. Third, we did not assess ease in navigating each website which is an important consideration for using the internet. The only action available to respondents was the ability to scroll up or down on each screenshot to view additional information. Fourth, we included only 2 
websites for review, while we recognize that there are numerous sites that provide information about COPD. However, we selected websites of 2 prominent and widely recognized organizations that provide specific information about COPD. Inclusion of additional websites would have extended the survey time and may possibly have affected the favorable completion rate.

\section{Conclusion}

This report details, for the first time, how patients with COPD use the internet to obtain health information and their assessment of disease content on 2 COPD educational websites. Medical information on the internet is used increasingly by patients and family members to learn about their health concerns. As websites offer a marketplace of online medical information, consumers will determine by their viewing experiences which sites are user-friendly and provide value. Greater knowledge about a chronic condition, like COPD, may empower individuals to participate in collaborative self-management with the goal to achieve better outcomes. ${ }^{21,22}$ Our findings offer practical information that can be used by individuals and organizations to modify/enhance information about COPD on their websites and by health care professionals to recommend specific websites to interested patients.

\section{Acknowledgments}

All named authors meet the International Committee of Medical Journal Editors (ICMJE) criteria for authorship for this manuscript by contributing to conception, design, or data processing; drafting and critically revising the manuscript; and approving this draft for submission and accepting responsibility for the contents within. Financial support for the study was provided by Sunovion Pharmaceuticals LLC to the CHEST Foundation.

\section{Declaration of Interest}

Donald A. Mahler has participated in Advisory Boards for AstraZeneca, Boehringer Ingelheim, GlaxoSmithKline, Mylan, Novartis, Sunovion, and Theravance. $\mathrm{He}$ is on the speakers' bureau for Boehringer Ingelheim, Grifols, and Sunovion. $\mathrm{He}$ has received royalties from Hillcrest Media for COPD: Answers to Your Question, 2015; CRC Press for Dyspnea: Mechanisms, Measurement, and Management, 3rd edition, 2014, and MAPI Research Trust and pharmaceutical companies for use of the baseline and transition dyspnea indexes. Frank Cerasoli is an employee of Medical Dynamics, New York, New York. Lindsay Della is an employee of University of Louisville, Louisville, Kentucky. Mark Rudzinski is principal of Rockpile Strategies LLC, LaGrange, Illinois. 


\section{References}

1. Mahler DA, Petrone RA, Krocker DB, Cerasoli F. A perspective of web-based information for patients with chronic lung disease. Ann Am Thorac Soc. 2015;12(7):961-965.

doi: https://doi.org/10.1513/AnnalsATS.201502-104PS

2. Fisher JH, O'Connor D, Flexman AM, Shapera S, Ryerson CJ. Accuracy and reliability of internet resources for information on idiopathic pulmonary fibrosis. Am J Respir Crit Care Med. 2016; 194(2):218-225.

doi: https://doi.org/10.1164/rccm.201512-2393OC

3. Luckett T, Disler R, Hosie A, et al. Content and quality of websites supporting self-management of chronic breathlessness in advanced disease: a systematic review. NPJ Prim Care Respir Med. 2016;26:16025.

doi: https://doi.org/10.1038/npjpcrm.2016.25

4. Daraz L, MacDermid JC, Wilkins S, Gibson J, Shaw L. The quality of websites addressing fibromyalgia: an assessment of quality and readability using standardized tools. BMJ Open. 2011;1:e000152.

5. Rice K, Bourbeau J, MacDonald R, Wilt TJ. Collaborative self-management and behavioral change. Clin Chest Med. 2014;35(2):337-351.

doi: https://doi.org/10.1016/j.ccm.2014.02.004

6. Martinez CH, St Jean BL, Plauschinat CA, et al. Internet access and use by COPD patients in the National Emphysema/COPD Association survey. BMC Pulm Med. 2014;14:66.

7. Delgado CK, Gazzotti MR, Santoro IL, Carvalho AK, Jardim JR, Nascimento $O A$. Internet use for health-care information by subjects with COPD. Respir Care. 2015;60(9):1276-1281. doi: https://doi.org/10.4187/respcare.03716

8. Brooks SM. Task force on surveillance for respiratory hazards in the occupational setting. ATS News. 1982;8:12-16.

9. Vogelmeier CF, Criner GJ, Martinez FJ, et al. Global strategy for the diagnosis, management, and prevention of chronic obstructive lung disease 2017 report. Am J Respir Crit Care Med. 2017;196:557-582.

doi: https://doi.org/10.1164/rccm.201701-0218PP

10. AAPOR guidance for IRBs and survey researchers. American Association of Public Opinion Research website. https://www. aapor.org/Standards-Ethics/Institutional-Review-Boards/ Full-AAPOR-IRB-Statement.aspx. Accessed November 4, 2016. Published 2014.

11. Research Now Panel Book: Panel recruitment. Research Now website. 2016. Accessed August 2017. Published 2016. https:// www.researchnow.com/wp-content/uploads/2017/11/PanelBook-10-17-WEB-1.pdf
12. Lung health \& diseases: chronic obstructive pulmonary disease (COPD). American Lung Association website. http://www. lung.org/lung-health-and-diseases/lung-disease-lookup/copd/. Accessed Feb 2017. Published 2016.

13. Understanding COPD. COPD Foundation website. Available from: http://www.copdfoundation.org. Accessed February 2017. Published 2016.

14. Eysenbach G. Improving the quality of web surveys: the checklist for reporting results of internet e-surveys (CHEERIES). J Med Internet Res. 2004;6(3):e34.

doi: https://doi.org/10.2196/jmir.6.3.e34

15. Centers for Disease Control and Prevention(CDC). 2010 National Ambulatory Medical Care Survey. CDC website. htttps://www.cdc.gov/nchs/data/ahcd/NAMCS_30A_2010.pdf Accessed July 2017.

16. Fox S, Duggan M. Health online 2013. Pew Research Center website. http://pewinternet.org/Reports/2013/Health-online. aspx. Accessed July 2017. Published January 2013.

17. Rennard S, Decramer M, Calverley PM, et al. Impact of COPD in North America and Europe in 2000: subjects' perspective of Confronting COPD International Survey. Eur Respir J. 2002;20(4):799-805.

doi: https://doi.org/10.1183/09031936.02.03242002

18. Miravitlles M, Ferrer J, Baro E, lleonart M, Galera J. Differences between physician and patient in the perception of symptoms and their severity in COPD. Respir Med. 2013;107(12):1977-1985. doi: https://doi.org/10.1016/j.rmed.2013.06.019

19. Hernandez P, Balter MS, Bourbeau J, Chan CK, Marciniuk DD, Walker SL. Canadian practice assessment in chronic obstructive pulmonary disease: respiratory specialist physician perception versus patient reality. Can Respir J. 2013;20:97-105. doi: https://doi.org/10.1155/2013/369019

20. Celli B, Blasi F, Gaga M, et al. Perception of symptoms and quality of life - comparison of patients' and physicians' views in the COPD MIRROR study. Int J COPD. 2017;12:2189-2196. doi: https://doi.org/10.2147/COPD.S136711

21. Zwerink M, Brusse-Keizer M, van der Valk PD, et al. Selfmanagement for patients with chronic obstructive pulmonary disease. Cochrane Database Syst Rev. 2014;19;3:CD002990. doi: https://doi.org/10.1002/14651858.CD002990.pub3

22. Tan JY, Chen JX, Liu XL, et al. A meta-analysis on the impact of disease-specific education programs on health outcomes for patients with chronic obstructive pulmonary disease. Geriatr Nurs. 2012;33:280-296. doi: https://doi.org/10.1016/j.gerinurse.2012.03.001 